\title{
Clinicopathological study of leiomyomas in hysterectomy specimens
}

\author{
Manpreet Kaur ${ }^{1 *}$, Rajiv Kamal Gupta², Simrat Jit Kaur², Panchampreet Kaur ${ }^{3}$
}

\begin{abstract}
${ }^{1}$ Department of Obstetrics and Gynaecology, Government Medical College, Patiala, Punjab, India
${ }^{2}$ Department of Pathology, Government Medical College, Patiala, Punjab, India

${ }^{3}$ Department of Obstetrics and Gynaecology, Max Superspeciality Hospital, Saket, New Delhi, India
\end{abstract}

Received: 25 January 2018

Accepted: 28 February 2018

\author{
*Correspondence: \\ Dr. Manpreet Kaur, \\ E-mail: kalramanpreet@yahoo.com
}

Copyright: (C) the author(s), publisher and licensee Medip Academy. This is an open-access article distributed under the terms of the Creative Commons Attribution Non-Commercial License, which permits unrestricted non-commercial use, distribution, and reproduction in any medium, provided the original work is properly cited.

\begin{abstract}
Background: Leiomyomas are benign tumors of smooth muscle cells commonly encountered in women of reproductive age group. Aim of this study was to conduct a histopathological study of leiomyomas in hysterectomy specimens and to correlate them with clinical findings.

Methods: A prospective study was done on 130 hysterectomy specimens clinically diagnosed as leiomyoma. The specimens were subjected to histopathological examination.

Results: In this study, the most common age group was 31-50 years (87.69\%). Most common complaint was menorrhagia (51.54\%). In endometrium, the most common histopathological diagnosis was proliferative phase $(46.15 \%)$ followed by endometrial hyperplasia $(19.23 \%)$. The most common secondary change was hyalinization and the most common site was intramural (62.9\%).

Conclusions: Hysterectomy is a commonly performed procedure in the management of uterine leiomyomas. The ultimate diagnosis and prognosis depends on the histopathological examination; therefore, every operated specimen must be subjected to histopathology.
\end{abstract}

Keywords: Hysterectomy, Histopathology, Leiomyoma

\section{INTRODUCTION}

Leiomyomas are the most common uterine neoplasms. ${ }^{1}$ The clinical presentation of leiomyomas depends on their size and location. ${ }^{2}$ They cause many signs and symptoms, the most common of which are pain, a sensation of pressure, and abnormal uterine bleeding. Leiomyomas need hormonal milieu for their growth and maintenance as evidenced by the molecular studies that they exhibit more estrogen receptors than normal myometrium. ${ }^{3}$ The cut surface of leiomyoma is white to tan, with a whorled trabecular pattern. On microscopic examination, it consists of whorled, anastomosing fascicles of uniform fusiform smooth muscle cells. Leiomyomas are one of the most common clinical indications of hysterectomy. Therefore, it is necessary to do histopathological examination for confirmation and optimal patient management.

\section{METHODS}

The study was conducted on 130 hysterectomy specimens clinically diagnosed as leiomyoma. The specimens were received in the Department of Pathology from the Department of Obstetrics and Gynaecology, Government Medical College and Rajindra Hospital, Patiala. The study proposal and procedures were approved by the Ethical Committee of Government Medical College, Patiala. All the specimens were fixed in $10 \%$ formalin. After gross examination and tissue processing, blocks were made. Sections of $4 \mu \mathrm{m}$ thickness were cut from these blocks and were stained with routine Haematoxylin 
and Eosin stain and examined under microscope. The clinical data and histopathological findings were recorded. Chi-square test was used to determine the statistical significance. A p-value of $<0.05$ was considered statistically significant.

\section{RESULTS}

Out of 130 cases studied, 80 cases (61.54\%) of leiomyoma were seen in the age group 41-50 years, followed by 34 cases $(26.15 \%)$ in the age group $31-40$ years. In the age group 51-60 years, 15 cases $(11.54 \%)$ were seen and 1 case $(0.77 \%)$ was seen in the age group 61-70 years (Table 1). Maximum cases of leiomyoma were seen in the age group 31-50 years (87.69\%).

Table 1: Age-wise distribution of patients with leiomyoma.

\begin{tabular}{|lll|}
\hline Age group (years) & Leiomyoma $(\mathrm{n}=\mathbf{1 3 0})$ \\
\hline $31-40$ & Number & Percent \\
\hline $41-50$ & 34 & 26.15 \\
\hline $51-60$ & 80 & 61.54 \\
\hline $61-70$ & 15 & 11.54 \\
\hline Total & 1 & 0.77 \\
\hline
\end{tabular}

Patients with leiomyoma presented with multiple complaints. Most common complaint was menorrhagia (51.54\%) followed by pain lower abdomen $(48.46 \%)$ and irregular bleeding (18.46\%) (Figure 1).

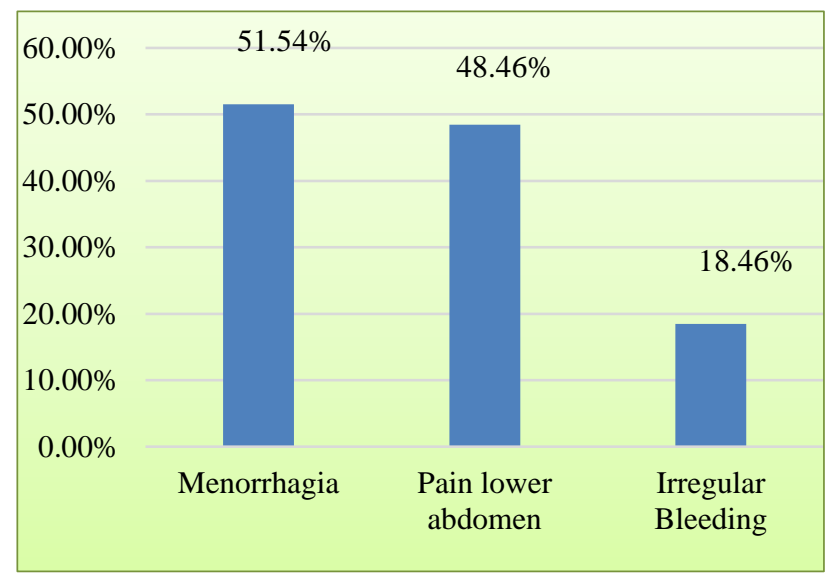

Figure 1: Various complaints of patients with leiomyoma.

In this study, 127 cases $(97.69 \%)$ were seen in multiparous women while 3 cases $(2.31 \%)$ were seen in nulliparous women.

In endometrium, the most common histopathological diagnosis was proliferative phase, seen in 60 cases $(46.15 \%)$ followed by endometrial hyperplasia in 25 cases (19.23\%). Other diagnosis included secretory phase in 22 cases $(16.92 \%)$, atrophic endometrium in 9 cases $(6.92 \%)$. endometrial breakdown in 2 cases $(1.54 \%)$, disordered proliferative phase in 5 cases (3.85\%), endometrial polyp in 6 cases $(4.62 \%)$ and chronic endometritis in 1 case $(0.77 \%)$. In 36 cases $(27.69 \%)$ adenomyosis was seen in myometrium along with leiomyoma.

In this study secondary changes in leiomyoma were seen in 15 cases $(11.54 \%)$. The most common secondary change observed was hyalinization $(5.38 \%)$ followed by calcification (3.85\%). Myxomatous change was seen in $3.08 \%$, cystic change in $2.31 \%$, haemorrhage in $0.77 \%$ and infection in $0.77 \%$ cases.

Distribution of site of leiomyoma was seen. Some patients presented with multiple leiomyomas. The most common site of leiomyoma was intramural (62.9\%) followed by submucosal $(21.8 \%)$ and subserosal $(15.3 \%)$ (Figure 2).

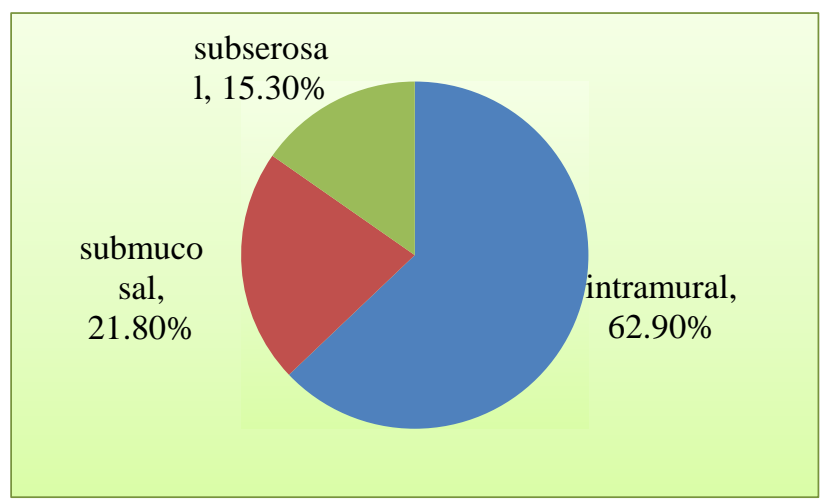

Figure 2: Site of leiomyoma.



Figure 3: Gross picture showing enlarged uterus with submucosal fibroid

Site of leiomyoma was correlated with various complaints of patients. In our study, $69.2 \%$ cases of subserosal fibroid ( $\mathrm{p}$ value $=0.000), 45.8 \%$ cases of intramural fibroid $(\mathrm{p}$ value $=0.015$ ) and $37.8 \%$ cases of submucosal fibroid ( $\mathrm{p}$ value $=0.982$ ) presented with pain lower abdomen. Highly significant correlation was found between pain lower abdomen and subserosal fibroids. 


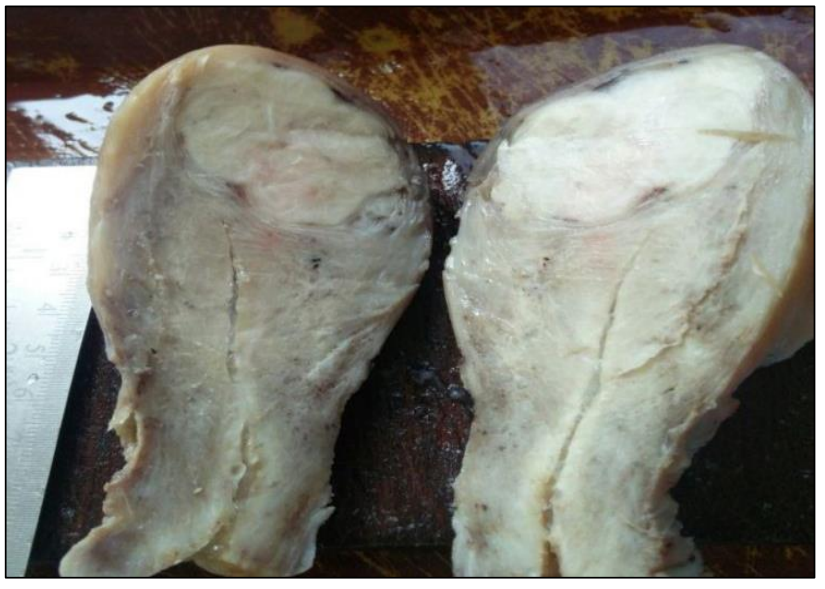

Figure 4: Cut surface is white to tan with whorling pattern.

In this study, $42.3 \%$ cases of subserosal fibroid ( $\mathrm{p}$ value $=$ $0.628), 55.1 \%$ cases of intramural fibroid ( $\mathrm{p}$ value $=$ 0.000 ) and $35.1 \%$ cases of submucosal fibroid ( $\mathrm{p}$ value $=$ $0.691)$ presented with menorrhagia suggesting significant correlation of menorrhagia with intramural fibroids.

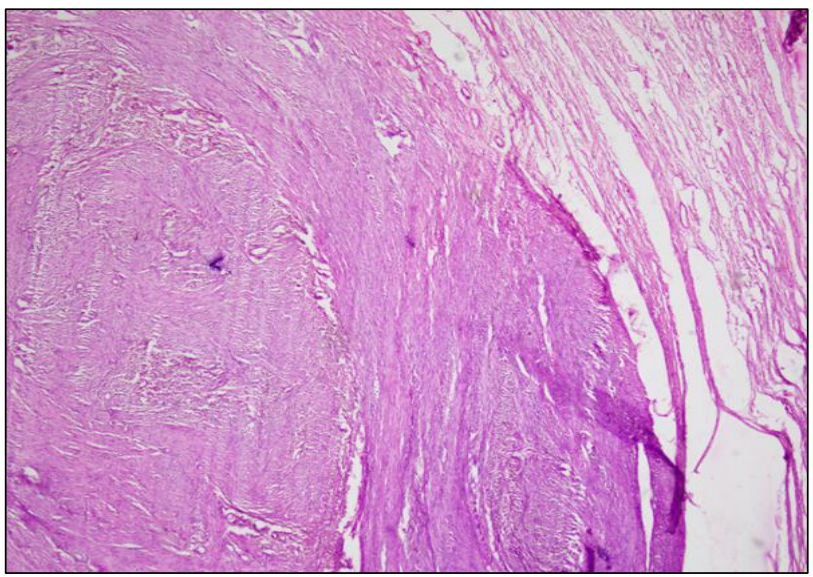

Figure 5: Photomicrograph of Leiomyoma showing whorled, anastomosing fascicles of fusiform smooth muscle cells (H\&E X 100).

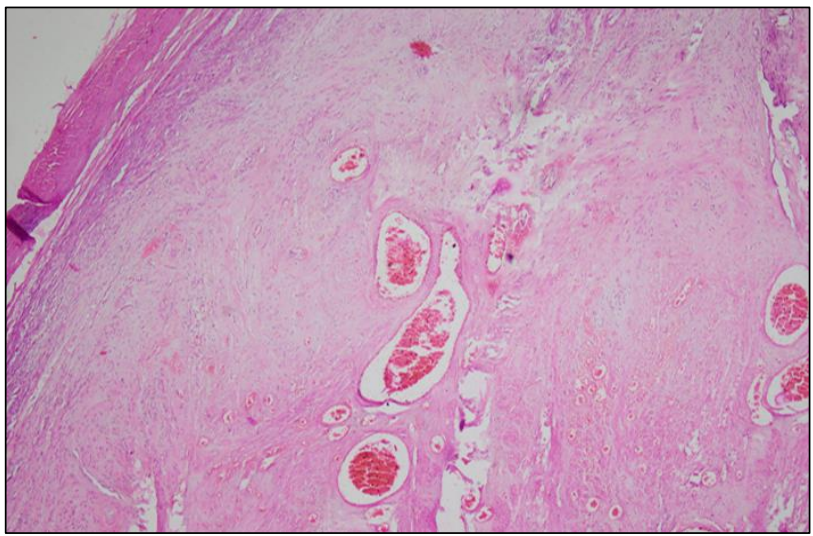

Figure 6: Photomicrograph of Leiomyoma showing hyalinization (H\&E X 100).

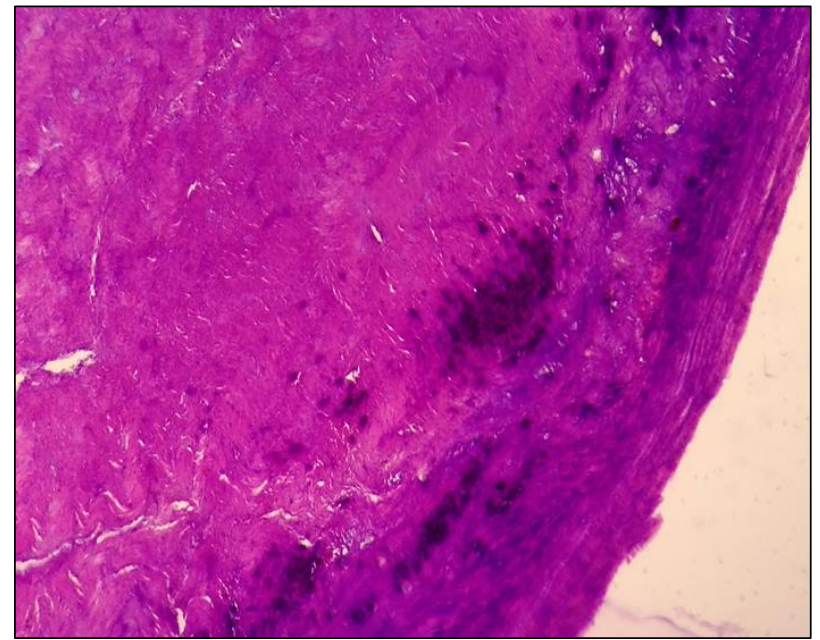

Figure 7: Photomicrograph of Leiomyoma showing calcification (H\&E X 100).

In the present study, $7.7 \%$ cases with subserosal fibroid $(\mathrm{p}$ value $=0.320), 13.1 \%$ cases of intramural fibroid $(\mathrm{p}$ value $=0.689$ ) and $56.8 \%$ cases of submucosal fibroid presented with irregular bleeding $(p$ value $=0.000)$. Highly significant correlation was seen between submucosal fibroids and irregular bleeding.

\section{DISCUSSION}

Leiomyomas are mostly seen in reproductive age group and are hormone sensitive smooth muscle tumours. ${ }^{4}$ In the present study maximum cases of leiomyoma were seen in the age group $31-50$ years $(87.69 \%)$. This was comparable to the studies conducted by Gowri et al, Geethamala et al and other studies (Table 2). ${ }^{5,7}$

Table 2: Comparison with other studies for most common age-group.

\begin{tabular}{|ll|}
\hline $\begin{array}{l}\text { Author and year of } \\
\text { Study }\end{array}$ & $\begin{array}{l}\text { Percentage of patients in } \\
31-50 \text { years age group }\end{array}$ \\
\hline Gowri et al $^{5}$ & $90.3 \%$ \\
\hline Dayal et al $^{6}$ & $78.0 \%$ \\
\hline Geethamala et al $^{7}$ & $90.23 \%$ \\
\hline Dayal and Nagrath & $82.83 \%$ \\
\hline Present study & $87.69 \%$ \\
\hline
\end{tabular}

In this study most common complaint of patients with leiomyoma was menorrhagia $(51.54 \%)$ followed by pain lower abdomen (48.46\%) and irregular bleeding $(18.46 \%)$. This was similar to the studies conducted by Gowri et al, Dayal et al and Dayal and Nagrath (Table 3). ${ }^{5.6 .8}$

In the present study, 127 cases $(97.69 \%)$ were seen in multiparous women while 3 cases $(2.31 \%)$ were seen in nulliparous women. In a study conducted by Geethamala et al, $93.8 \%$ cases were seen in multiparous women and $1.6 \%$ in nulliparous. ${ }^{7}$ Similar results were seen in a study 
conducted by Begum and Khan, Chethana et al and Lahori et al. ${ }^{9-11}$

Table 3: Comparison with other studies for chief complaints.

\begin{tabular}{|c|c|c|}
\hline $\begin{array}{l}\text { Author and year of } \\
\text { Study }\end{array}$ & Menorrhagia & $\begin{array}{l}\text { Pain lower } \\
\text { abdomen }\end{array}$ \\
\hline Gowri et $\mathrm{al}^{5}$ & $49.03 \% \%$ & $30.5 \%$ \\
\hline Dayal et $\mathrm{al}^{6}$ & $55.6 \%$ & $21.1 \%$ \\
\hline Dayal and Nagrath ${ }^{8}$ & $60.86 \% \%$ & $30.20 \%$ \\
\hline Present study & $51.54 \%$ & $48.46 \%$ \\
\hline
\end{tabular}

In this study, the most common histopathological diagnosis in endometrium was proliferative phase (46.15\%) followed by endometrial hyperplasia (19.23\%). This was comparable with the study conducted by Geethamala et al, in which proliferative phase was seen in $50.7 \%$ and simple hyperplasia in $22.7 \% .^{7}$ In a study conducted by Dayal and Nagrath, proliferative phase was seen in $48.51 \%$ and simple hyperplasia in $5.03 \%$ while in a study by Gowri et al, proliferative phase was seen in $46.3 \%$ and simple hyperplasia was seen in $22.8 \% .^{8,5}$ Proliferative phase and endometrial hyperplasia is seen commonly possibly due to hyper-estrogenic state.

In the present study, adenomyosis was seen in myometrium along with leiomyoma in $27.69 \%$ cases. This was similar to the studies by Gowri et al $(29 \%)$ and Kulkarni et al $(16 \%))^{5,12}$ Coexistence of these lesions is due to unopposed estrogen and entrapment of glands within hypertrophied myometrium.

In this study secondary changes in leiomyoma were seen in 15 cases $(11.54 \%)$. The most common secondary change observed was hyalinization $(5.38 \%)$ followed by calcification $(3.85 \%)$. Myxomatous change was seen in $3.08 \%$, cystic change in $2.31 \%$, haemorrhage in $0.77 \%$ and infection in $0.77 \%$ cases. The results were comparable to the study conducted by Lahori et al in which secondary changes were seen in $16.46 \%$ cases. ${ }^{11}$ Among these, $6.33 \%$ showed hyaline change which constituted the most common secondary change, $3.8 \%$ showed myxoid change, $3.8 \%$ showed calcification, $3.8 \%$ showed cystic and $2.53 \%$ demonstrated red (carneous) degeneration. Jung et al found secondary changes in $9.2 \%$ cases and the most common change was hyaline degeneration $(5.7 \%){ }^{13}$ Gowri et al reported secondary changes in $23.6 \%$ cases with hyalinization (16.9\%) being the commonest secondary change followed by cystic $(3.5 \%)$ and myxoid (1.6\%) change. ${ }^{5}$ Abraham and Saldanha observed secondary changes in $22.2 \%$ cases, among these hyaline changes was most common. ${ }^{14}$ The degenerative or secondary changes in leiomyomas occur due to inadequate blood supply. The type of secondary changes depends on the rapidity and degree of vascular insufficiency. ${ }^{15}$ Also these changes usually occur in an old mature lesion, therefore careful histopathological sampling should be done to rule out any malignant changes. The most common site of leiomyoma in the present study was intramural $(62.9 \%)$ followed by submucosal $(21.8 \%)$ and subserosal $(15.3 \%)$. Intramural was the most common site of leiomyoma in a study by Kulkarni et al $(60 \%)$ and Lahori et al $(57.43 \%)$ and Gowri et al $(48 \%){ }^{12,11,5}$

Most of the cases with subserosal fibroid presented with pain abdomen, while most of the cases with submucosal fibroid presented with irregular bleeding. Subserosal fibroids can cause pain due to compression or torsion (if they are pedunculated). Submucosal fibroids can cause compression of the overlying endometrium and compromise of its vascular supply.

\section{CONCLUSION}

Hysterectomy is a commonly performed procedure in the management of uterine leiomyomas. The ultimate diagnosis and prognosis depends on the histopathological examination; therefore, every operated specimen must be subjected to histopathology. The clinicopathological correlation is mandatory for optimal patient management.

Funding: No funding sources

Conflict of interest: None declared

Ethical approval: The study was approved by the Institutional Ethics Committee

\section{REFERENCES}

1. Payson M, Leppert P, Segars J. Epidemiology of myomas. Obstet Gynecol Clin North Am. 2006;33(1):1-11.

2. Bukulmez O, Doody KJ. Clinical features of myomas. Obstet Gynecol Clin N Am. 2006;33(1):6984.

3. Rosai J. Female reproductive system. In: Rosai and Ackerman's Surgical Pathology. $9^{\text {th }}$ ed. Missouri: Elsevier; 2004;2:1603-8.

4. Robboy SJ, Bentley RC, Butnor K, Anderson MC. Pathology and pathophysiology of uterine smoothmuscle tumors. Environmental Health Perspectives. 2000:779-84.

5. Gowri M, Mala G, Murthy S, Nayak V. Clinicopathological study of uterine leiomyomas in hysterectomy specimens. J Evol Med Dent Sci. 2013;46(2):9002-9.

6. Dayal S, Kumar A, Verma A. Clinicopathologic correlation of leiomyoma with clinical findings and secondary changes in a rural population of North India. Am J Clin Pathol. 2014;141(2):275-9.

7. Geethamala K, Murthy VS, Vani BR, Rao S. Uterine leiomyomas: an ENIGMA. J Mid-life Health. 2016;7(1):22-7.

8. Dayal S, Nagrath A. Clinicopathological correlation of endometrial, myometrial and ovarian pathologies with secondary changes in leiomyoma. J Pathol Nepal. 2016;6(11):937-41. 
9. Begum S, Khan S. Audit of leiomyoma uterus at Khyber teaching hospital Peshawar. J Ayub Med Coll Abbottabad. 2004;16(2):46-9.

10. Chethana M, Kumar HML, Munikrishna M. Endometrial changes in uterine leiomyomas. J Clin Biomed Sci. 2013;3(2):72-9.

11. Lahori M, Malhotra AS, Khajuria A, Goswami KC. Clinicopathological spectrum of uterine leiomyomas in a state of Northern India: a hospital-based study. Int J Reprod Contracept Obstet Gynecol. 2017;5(7):2295-9.

12. Kulkarni MR, Dutta I, Dutta DK. Clinicopathological study of uterine leiomyomas: a multicentric study in rural population. J Obstet Gynecol India. 2016;66(1):412-6.

13. Jung JK, Koi MS, Jung BW, Lee HH, Choi HJ, Shin SK. A clinical analysis of uterine myoma. Korean J Obstet Gynecol. 1998;41(1):210-9.
14. Abraham J, Saldanha P. Morphological variants and secondary changes in uterine leiomyomas. Is it important to recognize them? Int $\mathrm{J}$ of Biomed Reseach. 2013;4(12):254-64.

15. Persaud V, Arjoon PD. Uterine leiomyoma. Incidence of degenerative change and correlation of associated symptoms. Obstet Gynecol. 1970;35:4326.

Cite this article as: Kaur M, Gupta RK, Kaur SJ, Kaur P. Clinicopathological study of leiomyomas in hysterectomy specimens. Int J Reprod Contracept Obstet Gynecol 2018;7:1509-13. 